Karşılaştırmalı Açıdan Türkiye'de ve Amerika'da Tarih Eğitimi: Hacettepe Üniversitesi Tarih Bölümü ve Western Illinois Üniversitesi Tarih Bölümü Üzerine Örnek Bir Çalışma*

History Education in Turkey and the United States from Comparative Perspective: A Case Study of the History Departments of Hacettepe University and Western Illinois University

\title{
Ramazan ACUN
}

Hacettepe Üniversitesi Edebiyat Fakültesi, E-posta: acun@hacettepe.edu.tr orcid.org/0000-0002-1841-045X

Article Info

\begin{tabular}{|c|c|}
\hline Article Type & Research \& Theoretical \\
\hline Received & 03.01 .2020 \\
\hline Accepted & 22.05 .2020 \\
\hline DOI & 10.17497/tuhed.669456 \\
\hline $\begin{array}{c}\text { Corresponding } \\
\text { Author }\end{array}$ & Ramazan ACUN \\
\hline Cite & 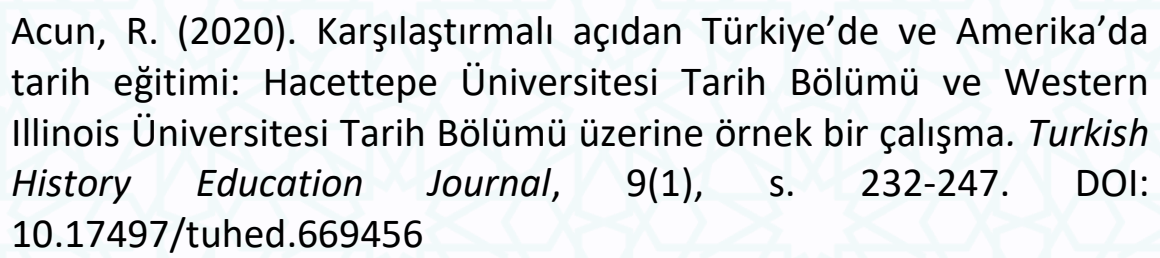 \\
\hline
\end{tabular}

* Bu çalışma, Hacettepe Üniversitesi Bilimsel Araştırma Projeleri Koordinasyon Birimi (BAP) tarafından bir Uluslararası Araştırma İşbirliği Projesi (Proje No: SBI-2018-17022) kapsamında desteklenmiştir. Uluslararası Tarih Eğitimi Sempozyumunda (ISHE 2019) bildiri olarak sunulmuş olup tam metin gönderilmemiştir. 
Öz: Güvenilir istatistikler olmamakla birlikte, Türkiye'de tarih mezunlarının diğer mesleklere kıyasla yüksek bir işsizlik oranına sahip olduğu bilinmektedir. Amerika Birleşik Devletlerinden ise tarih mezunlarının istihdam oranı diğer mesleklerden farklı değildir. Bu çalışmada bu farkın bir nedeninin eğitim programları olabileceği varsayılarak, Türkiye'den ve Amerika'dan seçilen iki üniversitenin tarih bölümleri üzerinde karşılaştırmalı örnek bir çalışma yapılmıştır. Bunlar Hacettepe Üniversitesi Tarih Bölümü ile Western Illinois Üniversitesi Tarih Bölümüdür. Çalışmada esas olarak söz konusu iki bölümün eğitim programları sistemik bakış açısıyla karşılaştırılmıştır. Bu çerçevede, Western Illinois Üniversitesinde 2018 yaz döneminde öğretim üyeleriyle görüşmeler ve derse katılım içeren bir araştırma gerçekleştirilmiştir. İki üniversite arasında mevcut bulunan bir akademik işbirliği anlaşması buna yardımcı olmuştur. Sonuç olarak, daha uzun süreli bir araştırma ile genişletilmesi gerektiği düşünülen şu temel bulgu elde edilmiştir: Türkiye' de tarih bölümü dersleri ve ders içerikleri "ideal tarihçi" göz ününe alınarak, mezunların mümkün olan en çok bilgiye sahip olmalarını sağlayacak şekilde düzenlenmiştir. Buna karşılık, $A B D^{\prime}$ 'de derslerin ve içeriklerinin belirlenmesinde mezuniyet sonrası kariyer seçenekleri ağılıklı olarak dikkate alınmakta olup öğretim üyesi başına düşen öğrenci sayısı (8) da bu hedefi destekleyecek şekildedir.

Anahtar Kelimeler: Üniversite Tarih Eğitimi, Üniversite Tarih Programları, Hacettepe Üniversitesi Tarih Bölümü, Western Illinois Üniversitesi Tarih Bölümü

\begin{abstract}
Although reliable statistics are not available, history graduates in Turkey are known to have a high unemployment rate compared to other professions. In the United States of America, however the employment rate of history graduates is no different from other professions. Assuming that one of the reasons for this difference in employment rates may be found in the design and implementation of educational programs, a comparative study has been carried out on two history departments one selected from Turkey and the other from the USA. These are the department of History, Hacettepe University, and Department of History, Western Illinois University. At the most basic level, this study is a comparison of the educational programs of these two departments using the systems approach. Within this framework, brief research involving class attendance and interviews with faculty members was conducted at the University of Western Illinois during the summer term in 2018. The study facilitated by the academic cooperation agreement between the two universities. As a result, the following basic finding which needs to be extended by longer-term research, has been obtained: The history courses and their contents in Turkey, seem to be arranged "an ideal historian" in mind so as to ensure that graduates get the most information possible. The determining factor, in the USA, on the other hand, seems to be widening career opportunities for graduates. The number of students per faculty member (8) supports this goal.
\end{abstract}

Keywords: University History Education, University History Programs, Hacettepe University History Department, Western Illinois University History Department

\title{
Extended Summary
}

\section{Purpose}

Significant progress has been made in the number and the quality of field-based studies on the history education in Turkey. Despite this progress in research, the longstanding unemployment problem of history graduates continues. Some estimates show that as much as $90 \%$ of history graduates remain unemployed for long periods of time. The case is 
the exact opposite in the United States (USA). In that country, more than $90 \%$ of the history graduates are able to find work and this rate is not lower than in other professions.

This project aims to investigate reasons for this big difference, other than the ones involving governmental policies regarding higher education and employment, using on-site direct observation methods.

\section{Method}

For this purpose, a case study of two departments, one selected from the USA and the other from Turkey, has been conducted using a comparative approach. These departments are the Department of History at Hacettepe University and the Department of History at the Western Illinois University.

The part of the research involving the Western History Department was conducted during the Summer of 2018, facilitated by the academic cooperation agreement between the two universities. Comparisons were made in terms of both structure and content of educational programs and their implementation processes. In this context, an online course, "American History Online", running at that time was attended and interviews were held with the instructors at Western.

\section{Results and Discussion}

The main results of this research can be listed as follows:

1. The undergraduate programs in both Hacettepe History Department and Western History Department were designed with an interdisciplinary approach; that is the programs include entry-level courses from other social sciences, such as Sociology and Psychology. In the Western History Department, the program has been modularized, taking into account the likely career goals that students may choose. Although there is no modular structure in Hacettepe History Department, students can create their own "modules" through elective courses. But the degree to which students are making the right decisions in terms of widening their carrier opportunities needs to be investigated.

2. A comparison of program outcomes based on the criteria for finding employment in different areas revealed that Hacettepe History is more ambitious.

3. Comparing the learning outcomes of the Historical Methods course common to both programs, taking into account the same criterion, however, yielded a different result: Hacettepe History Department seems to have defined the learning outcomes by taking into consideration an "ideal historian" working in isolation; Western History Department, on the other hand, highlighted effective communication skills such as demonstration, writing, explanation, and discussion.

4. The comparison of the programs on the basis of the implementation processes reveals the reason for this difference: Hacettepe History Department has had to carry out the instruction of History Methodology, which is one of the most important of the core courses, in classes of consisting 50-60 students, while Western History Department does classes with 7-10 students. From another point of view, while the number of students per permanent 
faculty member in the Hacettepe History Department is running around 42 , this number in the Western History Department on the other hand is less than one fifth that number, 8.

In the face of these results, it is clear that in the long run a comprehensive change in higher education policy in Turkey is needed. Considering that this has been widely discussed on various platforms and is inconclusive, it is therefore will not be elaborated on any further here.

But in the short run, history education programs may be revised and updated more frequently in line with the rapidly changing dynamics of the business world. In addition, preparing research projects that allow for student participation may help to develop knowledge and skills that will enable them to find work after graduation.

\section{Conclusion}

The history courses and their contents in Turkey, seem to be arranged "an ideal historian" in mind, working in isolation, so as to ensure that graduates get as much information as possible. The focus in the USA, in designing and implementing educational programs, on the other hand, seems to be on widening career opportunities of graduates. The number of students per faculty member, 8 , supports this goal.

Finally, for a more comprehensive result, this research needs to be extended by longer-term research covering a far larger number of history departments deemed to be representative from both countries and perhaps from other countries as well, such as the UK and Germany.

\section{Giriş}

Bir tarih diploması, şüphesiz, birçok ilgi çekici kariyer için bir basamak olabilir, tabii bunun için gerekli hazırlık yapıldıysa. Sağlıklı istatistikler olmamakla birlikte bazı tahminler, Türkiye'de tarih mezunlarının \%90 kadarının iş bulamadıklarını ve uzun süre işsiz kaldıklarını göstermektedir. Bu çalışma, tarih mezunlarının geniş bir meslek yelpazesinde istihdam edilebilmeleri sağlayacak bilgi ve becerilerin kazandırılması için gerekli zeminin oluşturulmasına yol açmayı amaçlamaktadır.

İstihdam alanlarının genişletilmesi iki yolla yapılabilir: Birincisi, yabancı dil ve ileri düzey bilgisayar kullanımı gibi becerilerin lisans eğitimi sırasında kazandırımasıdır ki Türkiye' de hali hazırda bazı bölümlerde bu yapılmaktadır. İkincisi, bu çalışmanın konusu olan, tarih eğitim programlarının günümüz toplum yapısına uygun yeni bilgi ve becerileri geliştirecek şekilde bütüncül bir bakış açısıyla tasarlanıp uygulanmasıdır.

Lisans eğitimi sırasında, ideal olarak, tarih öğrencileri sorunları ve olayları yüksek bir idrak seviyesinde anlama ve analiz etme becerisini geliştirirler. İş bulma bakımından önemli olan diğer nitelikler ise şunlardır: 
- Bir konuyu araştırmak üzere veri toplama

- Malzemeyi mantıklı ve tutarlı bir şekilde organize edebilme

- Malzemeden karşılaştırma ve analiz yoluyla yeni bilgi üretme

- Modern yöntem ve teknikleri kullanabilme ve beraber çalışabilme

- Fikirlerini yazılı ve sözlü olarak açık biçimde ifade edebilme

Hangi disiplinden eleman işe alıyor olursa olsunlar, bütün işverenler için bu beceriler konunun içeriğinden daha önemlidir. $A B D$ ve İngiltere gibi öğrencilerin bu tür becerileri geliştirdikleri ve mükemmelleştirdikleri ülkelerde, tarih mezunları çeşitli alanlarda kolayca iş bulabilmektedir. Dolayısıyla istihdam oranları çok yüksektir. Mesela, Ingiltere'de, tarih bölümü mezunlarının işsizlik oranı sadece \%5,9'dur (Tablo 1). İşverenler arasında muhasebe firmaları, bankalar, yükseköğretim kurumları, hukuk firmaları, danışmanlık firmaları, yayıncı şirketler, perakendeciler, okullar ve televizyon ve radyo yayıncıları bulunmaktadır (Snowdon, 2010). Bu da çok şaşırtıcı değildir çünkü tarihçilerin bu alanlarda nasıl faydalı olabileceğine dair araştırmalar çok önceden başlamıştır (Kantrow, 1986; "Educating Historians for Business", 1983).

Tablo 1

Ingiltere'de Tarih mezunları ne iş yapıyor?

\begin{tabular}{lc}
\hline Mezunların Durumu & $\%$ \\
\hline Çalışıyor & 58.9 \\
Lisansüstü eğitime devam ediyor & 21.8 \\
Çalışyor + eğitime devam ediyor & 6.4 \\
İşsiz & 5.9 \\
Diğer & 7.0 \\
\hline
\end{tabular}

Benzer bir tablo ABD tarih mezunları için de geçerlidir (Sturtevant, 2017). Dahası, ABD Çalışma İstatistikleri Bürosu'nun verilerine göre, tarihçilerin istihdamının 2018'den 2028'ya kadar, tüm diğer mesleklerin ortalaması kadar, yani yaklaşık yüzde 6 oranında artacağı tahmin edilmektedir ("Bureau of Labor Statistics", 2018).

Tarih eğitimini iyileştirme çalışmalarının yanı sıra, tarihçilerin kariyer yelpazesini genişletebilmek için akademi dışında da girişimler vardır. Mesela, Amerikan Tarih Derneği (AHA), Tarihçiler İçin Kariyer Çeşitliliği adı verilen bir girişim başlatmıştır. Bu girişim kapsamında, yeni mezun tarihçilerin ve lisansüstü öğrencilerin Andrew W. Mellon Vakfı'nın desteği ile akademi içinde ve dışında bir dizi kariyer seçeneğine daha iyi hazırlanabilmeleri için yapılması gerekenler konusunda çalışılmaktadır. Bu çerçevede AHA, ABD’nin dört bir yanından otuz kadar tarih bölümü ile işbirliği halinde lisansüstü eğitim kültürü ve pratiğini araştırmaktadır. Buna dayalı olarak da doktora öğrencilerinin değişen ihtiyaçlarını karşılamak için ne yapılması gerektiğini belirlemeyi hedeflemektedirler ("AHA's Career Diversity", t.y.). AHA web sitesinde, ayrıca, tarihçilerin iş bulmaları için gerekli becerileri geliştirmelerine yardımcı olmak üzere çok sayıda araştırma makalesi, rehber ve elkitabı bulunmaktadır, Sturtevant (2017) buna gösterilebilecek iyi örneklerden biridir. 
Her ne kadar sistematik olarak toplanmış güvenilir istatistikler olmasa da, bazı tahminler, tarih mezunlarının istihdamı bakımından Türkiye ile İngiltere ve ABD arasında keskin bir karşıtlığa işaret etmektedir. Mesela, bir analize göre tarih mezunlarının sadece küçük bir kısmı özel sektörde öğretmen, akademisyen ve memur olarak iş bulabilmektedir. Mezunların \%90 kadarı olduğu tahmin edilen büyük bölümü ise uzun süreler için işsiz kalmaktadır. Bundan dolayı da hakaretler, zihinsel çöküşler ve gelecek için derin kaygı ile karşı karşıya kalmaktadırlar. Söz konusu analiz bulgularına göre, kısaca, Türkiye'de tarih mezunları, tarih mezunu olmanın bütün hayatlarının anlamsız hale gelmesi ile eşit olduğunu düşünmeye başlamaktadır ("Tarih Öğretmenliği Branş", 2016).

Büyük Üniversitelerimizden birinin Tarih Bölümü Başkanı olarak, tarih mezunlarının karşı karşıya kaldığı psikolojik stres ile ilgili doğrudan kendi gözlemlerim de bulunmaktadır: Örnek olarak, 2016-2017 Bahar Dönemi 68 mezun adayından ikisi, diğer adaylarla beraber kendileri için de başlatılmış bulunan mezuniyet sürecinin durdurulmasını istediler. Gerekçe, mezun olduklarında çeşitli kurumlardan aldıkları bursu kaybedecek olmalarıydı. Onların düşüncesine göre, küçük miktardaki bir burs bile işsiz bir mezun olmaktan daha iyi idi.

Bu iç karartıcı görünüme rağmen, bütün Türkiye'deki üniversitelerde açılmış bulunan 120 kadar tarih bölümü, hem de bazılarında ikili öğretim yapılmak suretiyle, her yıl binden fazla yeni mezun vermeye devam etmektedir. Bu yeni mezunlar şu anda 25 binin üzerinde olduğu tahmin edilen işsiz tarihçi toplamına katılmaktadır.

İşsiz tarihçi problemine yönelik çözüm önerileri arasında, açık ve uzaktan eğitim fakülteleri içinde yer alan tarih programlarının kapatılması, aynı bölüm içerisinde yer alan ikili lisans programlarının (I. Öğretim ve II. Öğretim) uygulanmasını ve Yükseköğretim Kurulu (YÖK) tarafından merkezi olarak belirlenen öğrenci kontenjanlarının düşürülmesi bulunmaktadır.

$\mathrm{Bu}$ öneriler, görüldüğü üzere, Türkiye'de yükseköğretim alanında bir politika değişikliğini ve tabii buna uygun olarak, Hükümet tarafından kanunlaştırma vs. şeklinde uzun vadeli uygulamalar gerektirmektedir. Bununla birlikte, bu ortamda tarih bölümlerinin kendilerinin de yapmaları gereken görevler olduğu şüphesizdir.

Bölümlerin üzerine düşen görevlerden biri, çeşitli alanlarda iş bulma konusunda adeta maymuncuk anahtar rolü oynayan, yukarıda kısa bir listesi verilen mezun niteliklerinin geliştirilmesi yönünde çalışma yapılmasıdır.

Mezun niteliklerinin geliştirilmesinde tarih bölümlerinin yapabileceği işlerden biri öğretim programlarının hızlı değişen iş piyasası göz önüne alınarak daha sık gözden geçirilip yenilenmesidir. Bu da tarih programlarının içeriğine ve nasıl uygulandığına daha yakından bakılmasını gerektirmektedir. Türkiye'de üniversite tarih programları ve uygulanması ile ilgili araştırmalar, uzun süre literatüre dayalı teorik çalışmalar olarak kalmıştır. Sayıları çok olmayan bu çalışmalarda, daha ziyade, tarih eğitiminin önemi, neden ve nası öğretilmesi gerektiği üzerine odaklanıldığı görülmektedir.

Tarih eğitimi alanında 1990 'ı hatta 2000'lı yıllara kadar uygulamadaki problemlerin tespiti ve bu problemlerin çözümüne yönelik saha çalışmaları son derece azdır. Günümüzde ise bu alanda hem teorik ve hem de saha çalışmalarına dayanan önemli bir literatür oluşmaya 
başlamıştır. (Demircioğlu ve Demircioğlu, 2017). Ağırlıklı olarak Türkiye'de tarih eğitimi ile ilgili araştırma, inceleme, eleştiri ve çeviri makalelere yer veren Türk Tarihi Eğitim Dergisi (Turkish History Education Journal (TUHED)), 2012 yılından beri yayındadır. Bu makalenin bildiri olarak sunulduğu, "Uluslararası Tarih Eğitimi Sempozyumu" (ISHE 2019) da yine 2010 yılından beri düzenli olarak toplanmaktadır. Bu ortamlarda, ortaöğretime kıyasla daha az olsa da üniversite tarih eğitimi de ele alınmaktadır. Süleyman Demirel Üniversitesi ev sahipliğinde gerçekleştirilen Türkiye'de Lisansüstü Tarih Programlarının Durumu (Sorunları ve Çözüm Yolları) başlıklı çalıştay ile 2017 yılında Türk Tarih Kurumunun organize ettiği Uluslararası Tarih Müfredatı Çalıştayı da Türkiye' de genel olarak tarih eğitimine özel olarak da üniversite tarih eğitimine verilen önemin arttığının göstergeleridir.

Bütün bu gelişmelere rağmen, Türkiye'de üniversite tarih mezunlarının \%90 oranındaki ezici çoğunluğunun işsizlik problemi devam etmektedir. Bu oran son istatistiklere göre, \%27.1 civarında olan genç işsizlik oranından çok daha yüksektir. Bu durum, Türkiye'de üniversite seviyesindeki tarih programlarının, mezunların iş piyasasında aranır hale getirecek bilgi ve beceriler kazandırılması açısından sıkı bir şekilde gözden geçirilmesi gerektiğini açıkça göstermektedir. Ancak bu konuyu doğrudan ele alan bir çalışma henüz bulunmamaktadır.

$\mathrm{Bu}$ çalışmada, bu boşluğun doldurulması hedeflenmiştir. Bunun için uluslararası karşılaştırmayı içeren örnek bir çalışma yapılması öngörülmüştür. Bu nitelikte bir çalışma Türkiye'de daha önce yapılmamıştır.

\section{Yöntem}

Bu araştırma, üniversite tarih eğitiminin, farklı ülkelerde bulunan iki bölüm üzerinden karşılaştırılmasını içeren mikro düzeyde örnek bir çalışmadır. Karşılaştırma, bütüncül (sistemik) bir bakış açısıyla yapılmıştır. Başka bir ifadeyle, karşılaştırma sadece programlar bazında (statik) değil, Acun (2011) tarafından daha önce önemi vurgulandığı üzere, uygulama süreci yani eğitimin dinamik yönünü de kapsayacak şekilde planlanmıştır. Bu amaçla da yerinde gözlem yapılması, bunun için de Türkiye'den ve ABD'den dünya üniversite sıralamaları bakımından birbirine yakın iki üniversitenin tarih bölümlerinin karşılaştırılması öngörülmüştür. Bunlar Hacettepe Üniversitesi Edebiyat Fakültesi Tarih Bölümü (Hacettepe Tarih) Western Illinois Üniversitesi Tarih Bölümüdür (Western Tarih).

Çalışma, 6 aylık bir uluslararası işbirliği projesi kapsamında gerçekleştirilmiştir. Hacettepe Üniversitesinde uluslararası işbirliği projelerinde yurt dışı araştırmalar için sağlanan destek 90 günle sınırlı olduğundan, Western Tarih'te yapılan araştırmanın bu süre içinde tamamlanması hedeflenmiştir. O yüzden, örnek çalışmanın tasarımında, hızlı yapılabilecek olması göz önüne alınan parametrelerden biri olmuştur.

Söz konusu bölümlerin eğitim programlarının karşılaştırılmasında, önce genel olarak program yeterlikleri ele alınmıştır. Daha sonra ise derslerin içeriği, öğrenme kazanımları ve öğretim süreci karşılaştırılmıştır. 
Öğretim süreçleri bakımından karşılaştırmada, temel olarak programlarda tanımlanan ders içerikleri, öğrenme çıktıları ve öğretim metotlarının uygulama süreci ile uyumluluğuna bakılmıştır. Bu amaçla, araştırma süresi içinde yerinde gözlem yapılmıştır: Bu çerçevede, Western Tarih'te 2018 yaz döneminde açık olan bir derse katılım ve öğretim üyeleriyle görüşmeler gerçekleştirilmiştir. Bu görüşmeler ağırlıklı olarak Western Tarihin kendi lisans ve yüksek lisans programlarını değerlendirdiği iki dâhili rapor (McNabb, 2017; Woel 2017) etrafında olmuştur. Hacettepe Tarih'le karşılaştırmada ağırıklı olarak bu iki rapordaki veriler kullanılmıştır.

Araştırma için ABD'de bulunan Western Illinois Üniversitesinin seçilmesinde rol oynayan temel etken, bu üniversite ile mensubu bulunduğum Hacettepe Üniversitesi arasında bir akademik işbirliği protokolünün bulunmasıdır. Ayrıca bu üniversitenin literatür taraması için geniş bir kütüphanesi ve bütün diğer $A B D$ üniversitelerinde olduğu gibi, elektronik kaynaklara Türkiye'deki üniversitelere kıyasla daha fazla erişim imkânı bulunmaktadır. Araştırmanın yapılacağı yaz aylarında da yaz okulu yer almaktadır.

Seçimde rol oynayan bir diğer etken, Western Tarih'in mezunlarına iş bulma konusuna önem veren ve bunun için özel çaba gösteren bölümlerden biri olmasıdır. Nitekim Bölüm Web sitesinde "Bir Tarihçi Mezun Olarak Ne Yapabilirsiniz?" başlıklı bir rehber bulunmaktadır ("What Can You", t.y.). Burada, mezunların iş bulmasına yardımcı olabileceği düşünülen araştırma raporları, kitaplar ve potansiyel işveren kurum, kuruluş ve şirketlerin web sitelerine bağlantılar yer almaktadır.

Araştırma için Western Tarih'in seçilmesinde bunlar kadar önemli bir diğer nokta da 2018 yaz döneminde, misafir araştırmacı (visiting research scholar) statüsünde araştırma yapmak ve eğitim faaliyetlerine katılmak üzere tarafıma davet yapılmış olmasıdır.

Daveti yapan Profesör Timothy Roberts, Oxford Üniversitesi Tarih Bölümünde doktora yapmıştır. Western Tarih'te ise profesör kadrosundadır. Burada lisans seviyesinde Amerikan Hukuk Tarihi, Amerikan Askeri Tarihi ve Amerikan İç Savaşı gibi dersler vermektedir. Lisansüstü seviyede ise seminer dersleri yürütmektedir. Ayrıca, genel olarak kendi üniversitesinin tarih programının geliştirilmesine birçok katkı yapmıştır.

Profesör Roberts, ayrıca, Türkiye'de 2002-2008 yılları arasında Bilkent Üniversitesinde Yardımcı Doçent kadrosunda Lisansüstü seviyede Amerikan Tarihi dersleri vermiş ve bu üniversitenin Amerikan Tarihi Programının koordinatörlüğünü yapmıştır. Dolayısıyla daveti yapan öğretim üyesi, Türkiye'de tarih öğretim programları ve uygulanması hakkında da bilgi sahibidir. Bu da onu bu proje kapsamında yürütülecek araştırma çerçevesinde karşılıklı görüş alışverişi için $A B D$ 'deki uygun kişi yapmaktadır.

\section{Bulgular}

Hacettepe Tarih ve Western Tarih hakkında kısa bilgiler şöyledir: Her iki bölümde de lisans ve yüksek lisans programları vardır. Hacettepe Tarih'in bunlara ilave olarak bir de doktora programı bulunmaktadır. Lisans programlarının disiplinler arası bir yaklaşımla 
tasarlandığı görülmektedir; sosyoloji, antropoloji, psikoloji ve ekonomi gibi bölümlerden giriş düzeyinde dersler içermektedir. Mezuniyet için öğrencilerin benzer sayıda krediyi toplamaları gerekmektedir.

Western Tarih'in lisans programında, Hacettepe Tarih'ten farklı olarak, dersler gruplanarak modüler hale getirilmiştir: Genel Tarih, Hukuk'a Hazırlık (Pre-Law) ve Öğretmen Eğitimi. Öğrenciler kendi kariyer hedeflerine göre, bu modüllerden birini seçmektedir. Hukuk'a Hazırlık modülü, hukuk alanında bir kariyer düşünenler için tasarlanmıştır. Mastır yapmak üzere hukuk fakültesine gitmek isteyenler bu modülü seçmektedir. Beş dersten oluşan temel dersler (core couses) bütün modüller için ortaktır. Temel derslerden biri, tabii olarak, Tarih Metodolojisidir (Historical Methods).

Her iki bölümün lisans programlarının, program yeterlilikleri Tablo 2'de karşılaştırmaya imkân verecek şekilde gösterilmiştir. ("Hacettepe Tarih Lisans”, t.y.; McNabb, 2017). Burada görüldüğü üzere, lisans program yeterlilikleri bakımından, iki bölüm arasında büyük bir fark yoktur. Geniş bir tarih bilgisine sahip olmak, tarihsel düşünmek, sorgulayıcı bakış açısı kazanmak, kaynakları tenkit etmek ve etkili bir biçimde kullanmak, bulguları yorumlarken etik kurallara uymak, açık ve anlaşılır iletişim kurmak, başkalarının düşünce ve eylemlerini anlamaya çalışmak gibi fiiller kullanılmıştır.

Bu nitelik ve becerilere sahip olmak, birçok alanda iş kapılarını ardına kadar açabilir. Yeterlik listesinin uzunluğuna bakarak Hacettepe Tarih'in program bazında daha iddialı olduğu rahatlıkla söylenebilir.

Tablo 2

Hacettepe Tarih ve Western Tarih Lisans Program Yeterlikleri

\section{\begin{tabular}{l|l} 
Hacettepe Tarih Western Tarih & We \\
\hline
\end{tabular}}

1. Tarih bilimiyle ilgili temel kavramları, tarihin diğer sosyal bilimlerle ilişkisini, benzerlik ve farklarını kavrar ve açıklar.

2. Temel tarih kaynaklarını, bunların dillerini ve özelliklerini bilir ve tenkit eder, tarihi kaynaklardaki verileri bilgisayar programları dahil bilimsel ve teknik ve yöntemlerle analiz edip değerlendirir.

3. Tarihi olayları kısa, orta ve uzun vadeli süreçler olarak kavrar ve değerlendirir.

4. Farklı tarih ekolleri tarafından üretilen tarihi bilgiyi yöntem ve içerik olarak karşılaştırır.

5. Küresel, bölgesel ve yerel ölçekte, siyasi, sosyal, ekonomik, kültürel, bilimsel ve teknolojik gelişmeleri izleyerek tarihi perspektiften açıklar ve değerlendir.

6. İçinde yaşadığı toplum dahil, tarihi süreçte şekillenmiş farklı toplum, kültür ve uygarlıkların bilgilerini edinir, yorumlar ve karşılaştırır.

7. Herhangi bir siyasi, sosyal veya ekonomik problemin anlaşılması için geçmişini araştırmak üzere proje döngüsünü kendi başına tamamlayabilir, bulguları yorumlayarak çözüm geliştirir.
1. Develop a body of historical knowledge with range and depth. /Derinlikli ve kapsamlı bir tarihsel bilgi bütünü oluşturur.

2. Think historically. / Tarihsel düşünür.

3. Understand, critically evaluate, and effectively use complex and often competing historical sources and interpretations./ Karmaşık ve sıklıkla birbiriyle çelişen tarihsel kaynakları ve yorumları anlar, eleştirel olarak değerlendirir ve etkin bir biçimde kullanır.

4. Communicate clearly and appropriately through various media and within different contexts, especially formal historical writing. / Çeşitli medya aracılığıyla ve farklı bağlamlarda özellikle de formel tarih yazımı bağlamında anlaşılır ve uygun şekilde iletişim kurar. 
8. Ekip çalışmasının gerekliliğinin farkında olarak ekip çalışması içinde lider veya ekip üyesi olarak görevler alır. Diğer sosyal bilim alanlarıyla ortaklaşa çalışmalar yürütür.

9. Tarihle ve diğer sosyal bilimlerle ilgili Türkçe ve yabancı dilde yayımlanmış bilimsel çalışmaları takip edip açıklar ve farklı verilerle uygulamasını tekrarlar; bildiri, makale ve proje raporu gibi çalışmaları hazırlar.

10. Sorgulayıcı bakış açısı kazanır, başkalarının düşünce ve eylemlerini anlamaya çalışır, başkalarıyla kolay iletişim kuracak kadar sosyalleşir, bulguları ve düşüncelerini etik bir tarzda sunar ve yorumlar.

5. Engage a diversity of viewpoints in a civil and constructive fashion. / Çok şeşitli bakış açılarına karşı medeni ve yapıcı bir tavır sergiler

Peki, program bazında yapılan bu karşılaştırmanın benzeri ders bazında yapıldığında nasıl bir manzara ortaya çıkıyor? Bunun için yine örnek olarak, her iki bölümün lisans programında ortak olan Tarih Metodolojisi (Historical Methods) dersinin öğrenme çıktıları karşılaştırılmıştır (Tablo 3).

Tablo 3

Tarih Metodolojisi (Historical Methods) Dersinin Öğrenme Çıktıları

\begin{tabular}{|c|c|c|}
\hline Hacettepe Tarih & & Western Tarih \\
\hline $\begin{array}{l}\text { 1. Bilgi alanı olarak tarihin } \\
\text { farkına varır } \\
\text { 2. Bilimsel tarihin çalışma } \\
\text { yöntemlerini yorumlar } \\
\text { 3. Birincil kaynakları ve } \\
\text { araştırma eserlerini ayırt } \\
\text { eder } \\
\text { 4. Birincil kaynakları } \\
\text { yorumlar } \\
\text { 5. Tarihin diğer bilimler } \\
\text { arasındaki yerini } \\
\text { yorumla. }\end{array}$ & 2 & $\begin{array}{l}\text { Recognize how to develop a body of historical knowledge / } \\
\text { Tarihsel bilgi birikimini nasıl kazanacağını bilir. } \\
\text { Demonstrate prudence in use of Internet sources and hypertext } \\
\text { links. / Internet kaynaklarını ve bağlantıları kullanırken ihtiyatlı ve } \\
\text { dikkatli davranır. } \\
\text { Construct and properly arrange a bibliography in accord with the } \\
\text { Chicago Manual of Style. / Chicago Tarzı El Kitabı'na uygun olarak } \\
\text { bir kaynakça oluşturur ve düzenler. } \\
\text { Explain the conceptual frameworks that professional historians } \\
\text { use when interpreting and evaluating significance, including } \\
\text { change and continuity over time, context, causality, and } \\
\text { contingency / Profesyonel tarihçilerin zaman içindeki değişim ve } \\
\text { süreklilik, bağlam, nedensellik ve beklenmedik durum dahil olmak } \\
\text { üzere önemli olanı yorumlarken ve değerlendirirken kullandıkları } \\
\text { kavramsal çerçeveleri açıklar. } \\
\text { Recognize the complex interplay between the political, socio- } \\
\text { economic, and cultural structures of macrohistory on the one } \\
\text { hand, and the individual and group agency of microhistory on the } \\
\text { other./ Bir yandan makro tarihin politik, sosyo-ekonomik ve } \\
\text { kültürel yapıları ile diğer yandan da mikro tarihin bireysel ve grup } \\
\text { rolleri arasındaki karmaşık etkileşimi tanır. } \\
\text { Identify the nature of primary and secondary sources, and be able } \\
\text { to distinguish between the two. / Birincil ve ikincil kaynakların } \\
\text { niteliklerini tanımlar ve ikisi arasında ayrım yapar. } \\
\text { Recognize that historians employ diverse epistemological and } \\
\text { interpretive templates when they draw on and evaluate primary } \\
\text { and secondary sources. / Tarihçilerin birincil ve ikincil kaynakları }\end{array}$ \\
\hline
\end{tabular}




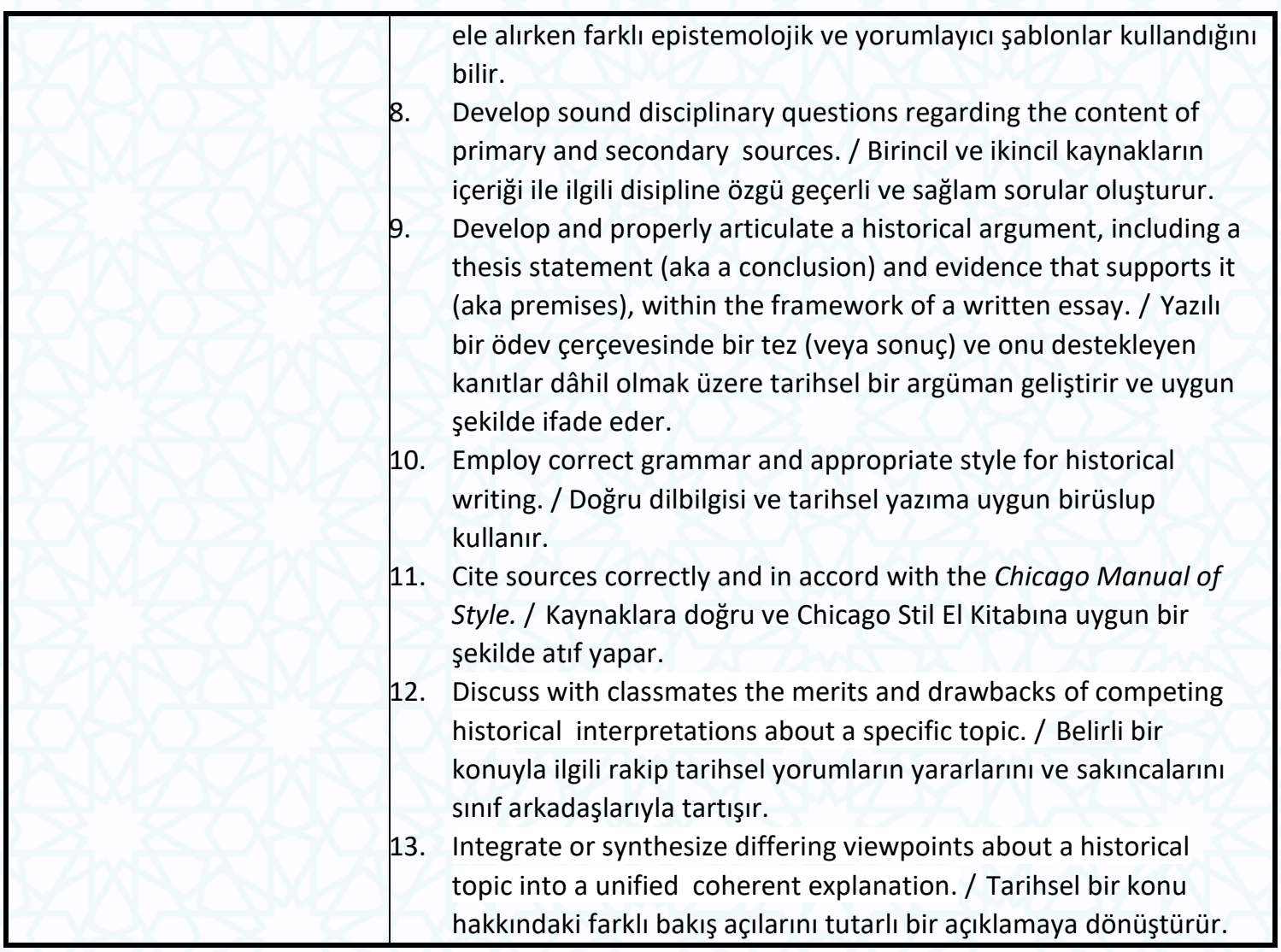

Tablo 3’teki öğrenme çıktılarının karşılaştırılması şöyle bir sonuç vermektedir. Hacettepe Tarih, Tarih Metodolojisi dersinin öğrenme çıtıllarını tanımlarken, farkına varır, ayırt eder ve yorumlar gibi bir tarihçinin belgeleri ve kitapları ile baş başa kaldığında yaptığı eylemleri öne çıkarmıştır. Bu durum aynı addaki yüksek lisans dersinde çok daha belirgindir (“Hacettepe Tarih Yüksek", t.y.).

Buna karşlık, Western Tarih, bunlara ilave olarak, ispat eder/gösterir (demonstrate), tartışır (discuss), açıklar (explain) ve tarihsel argüman geliştirir gibi somut olarak görülebilir ve başkalarıyla iletişim içeren fiillere de yer vermiştir. Etkili iletişim becerilerinin iş bulmada yaratacağı fark göz önüne alındığında, bu durumun önemi kendiliğinden ortaya çıkmaktadır.

Burada sorulması gereken soru şudur: Neden böyle bir sonuç ortaya çıkmıştır? Başka bir ifadeyle, çok iyi program yeterlikleri yazabilmiş bir bölüm, neden ders bazında aynı dikkati göstermemiş veya gösterememiştir? Bu sorunun cevabını bulabilmek için programların uygulama süreçlerine, dinamik boyuta odaklaşmak gerekmektedir. Bu da tabii gözlerimizi süreçte rol oynayan aktörlere, öğretim üyeleri ve öğrencilere daha yakından bakılması demektir.

Hacettepe Tarih'in öğretim üyesi/görevlisi sayısı 15, Western Tarih'in ise 10'dur, öğretim üyesi başına düşen öğrenci sayısı ise sırasıyla 42 ve 8 'dir. Başka bir ifadeyle Hacettepe Tarih'te öğretim üyesi başına düşen öğrenci sayısı Western Tarih'ten 5 kat daha fazladır.

Sınıf öğrenci sayıları da buna paraleldir. Örnek olarak, her iki bölümde de lisans programında zorunlu olan Tarih Metodolojisi (Historical Methods) dersini 2016-2017 akademik yılında alan öğrenci sayıları Tablo 4'te gösterilmiştir. 
Tablo 4

Tarih Metodolojisi (Historical Methods) Dersini Alan Öğrenci Sayıları

\begin{tabular}{llll}
\hline Bölüm & Dersin Kodu & Dönemi & Öğrenci Sayısı \\
\hline Hacettepe Tarih & TAR 131 & Güz (iki şube) & $61+56=117$ \\
Western Tarih & HIST 201 & Güz-Bahar & $10+7=17$ \\
\hline
\end{tabular}

Buna göre, Hacettepe Tarih'te bir dönemde iki şube halinde verilen derse kayıtlı öğrenci sayısı 117'dir. Buna karşılık Western Tarih'te iki ayrı dönemde dersi alan öğrenci sayısı toplamda sadece 17 'dir. Başka bir ifadeyle, buradaki fark yaklaşık 7 kattır.

Etkili iletişim becerilerinin geliştirilebilmesi için öğretim üyelerinin öğrencilerle bire bir ilgilenmesi gerekir. Bunun da 50-60 hatta bazı durumlarda 100 kişilik sınıflarda yapılamayacağı açıktır. O yüzden Hacettepe Tarih, Tarih Metodolojisi dersinin öğrenme çıktılarını yalnız çalışan "ideal tarihçi" göz önünde bulundurarak belirlemiştir. İdeal tarihçi, geniş bir yelpazede mümkün olan en fazla bilgiye sahip tarihçidir.

Program uygulama süreçleriyle ilgili bir başka önemli nokta, öğrenme çıktılarının (veya kazanımlarının) ölçülmesi ile ilgilidir. Western Tarihte hem lisans hem de yüksek lisans programında yeni bir uygulama olarak, tarih metodu ve seminer grubu derslerinde öğrenme çıktılarına ilişkin ölçme ve değerlendirme hem dönem başında hem de dönem sonunda olmak üzere iki kere yapılmaktadır. Böylece, öğrencilerin başlangıç durumuna göre dönem boyunca kaydettiği ilerlemeyi görmek mümkün olmaktadır. Bu uygulamanın diğer derslere de yayılması planlanmaktadır.

Açıktır ki, bu şekilde bir ölçme ve değerlendirmenin etkili yapılabilmesi için sınıf mevcutlarının uygun sayıda olması gerekir. Western Tarih'te bu sayı hiçbir şekilde 10'u geçmemektedir.

Hacettepe Tarih'te ise ölçme ve değerlendirme, dönem ortasında ara sınavlar dönem sonunda ise genel sınavlarla yapılmaktadır. Öğrencilerin başlangıç durumuna göre kaydettiği ilerlemeyi ölçme çalışması yapılmamaktadır. Yukarıda Tablo 4'te verilen öğrenci sınıf mevcudu ile ilgili örnekten, böyle bir çalışmanın istense bile etkili olarak yapılamayacağı açıkça bellidir.

Western Tarih lisans programı ders içerikleri üzerinde yapılan incelemede özellikle dikkat çeken bir nokta, seminer dersleri kapsamında, öğrencilere tarihi ve kültürel mirasla ilgili video hazırlama ödevlerinin verilmesi olmuştur. Bunun ilk bakışta göze çarpmayan önemi şuradadır: Günümüz dünyasında görsellik ve görsel teknolojiler giderek ağırlık kazanmakta ve bu çerçevede yeni meslekler ortaya çıkmaktadır. Örnek olarak YouTube adlı video paylaşım platformunda yapılan video yayınlarından çok iyi kazançlar elde edilebilmektedir. Bu yayınları yapanlara YouTuber adı verilmektedir. Bu işi bir meslek olarak görenler de vardır. Böyle bir dünyada, video hazırlama becerilerinin kazanılması, mezunların kariyer çeşitliği bakımından önemlidir. 
Bu alanda, Hacettepe Tarih'te "Tarih Eğitiminde Sınıf-Tarihi Mekân Entegrasyonu: Tarihi Mekân Gezilerinin Eğitsel Materyale (Video) Dönüştürülmesi" adlı yine Hacettepe Üniversitesi BAP desteği ile bir proje yürütülmektedir. ${ }^{1}$ Proje kapsamında üretilen video çekimlerine, öğrenciler doğrudan katılımsılardır. Bunun da sonuç olarak, öğrencilerin kariyer gelişimine katkı yapması beklenmektedir. Projeye başlangıçtan itibaren aktif katılan lisans ve lisansüstü öğrenci sayısı 7'dir. Bu da Western Tarih'in sözü edilen seminer dersini alan öğrenci sayısına yakındır. Bölümün sahip olduğu toplam öğrencisi sayısına kıyasla bu sayı az görünebilir. Ancak çalışma hem Hacettepe Tarih hem başka tarih bölümleri için model bir uygulama niteliği kazanabilir. Gerçekten de proje kapsamında üretilen videoların sosyal medyada daha yakında paylaşılan ilk birkaç bölümü kısa sürede on binden fazla izlenme ve beğeni sayılarına ulaşmıştır. ${ }^{2}$

Uygulama süreçlerinin doğrudan gözlemlenmesine gelince, Western Tarih'te, 20172018 Yaz Döneminde açılmış bulunan iki dersten biri olan “U.S. History Online” adlı derse aktif katılım gerçekleştirilmiştir. Ders, Profesör Timothy Roberts tarafından, dersin adından da anlaşılacağı üzere, online olarak verilmektedir. Dersi alan öğrencisi sayısı söz konusu dönemde 7'dir.

Derste OpenStaX koleji tarafından hazırlanmış U.S. History (Corbet, 2014) adlı kitap okutulmaktadır. Yüz yüze yapılan derslerde olduğu gibi, bu derste de öğrenciler çeşitli alıştırmalar yapmakta ve soru cevaplamaktadırlar. Bunlara ilave olarak, haftada iki kere, dersi veren öğretim üyesi tarafından yönetilen canlı etkileşimli oturumlar yer almaktadır. Öğretim üyesi, genellikle güncel bir olayla bağlantılı olarak sorduğu soruyla oturumu başlatmaktadır. Örnek olarak, Amerika'da resmi tatil olan "Memorial Day"e denk gelen oturum, "What is Decoration Day?" sorusuyla başlamıştır. Decoration Day, Memorial Day'in önceki adıdır; ülkeleri için ölen Amerikan askerlerinin hatırasına saygı maksadıyla o gün mezarlarının çiçeklerle süslenmesinden dolayı bu adı almıştır.

Canlı oturumlarda, geçmiş olaylar, hiçbir kaygı taşımadan eleştirel bir bakışla ele alınmaktadır. Mesela, Christopher Columbus'un 1492'de Amerika'yı keşfinin, diğer sonuçları yanında, Amerikan yerlilerinin Batııılar tarafından büyük bir kıyımına da yol açtığı rahatlıkla tartışılabilmektedir. Zaman zaman da "what if"le başlayan karşı olgusal (counter factual) sorulara cevap aranmaktadır. Örnek: “Eğer Amerika'yı önce Müslümanlar keşfedip yerleşseydi bugün kıtanın görünümü nasıl olurdu?"

Bu türden güncele bağlanan tartışmaların, Hacettepe Tarih'te olduğu gibi kalabalık sınıflarda yapılması neredeyse imkânsız görünmektedir. Çünkü böyle bir tartışma kısa sürede belli bazı siyasi ve ideolojik grupların birbirlerine karşı baskın çıkmaya çalıştığı kısır çekişmelere dönüşmektedir. Bu da sonuç olarak öğrencilerin öğrenme verimliliğini düşürüp kariyer gelişimlerine sekte vurmaktadır.

\footnotetext{
${ }^{1}$ Hacettepe Üniversitesi Bilimsel Araştırma Projeleri Koordinasyon Birimi Kapsamlı Araştırma projesi; Proje No: SBA-2017-11183; Yürütücü: R. Acun.

${ }^{2}$ Fakir Seyyahlar YouTube Kanalı: https://www.youtube.com/channel/UCR38Wrs-laOVqMgPMNVsqkg; Fakir Seyyahlar Facebook Sayfası: Erişim: (13.05.2020) https://www.facebook.com/fakirseyvahlar
} 


\section{Sonuç}

$\mathrm{Bu}$ araştırma, İngiltere ve ABD gibi gelişmiş ülkelerde Tarih mezunlarının \%90'ı iş bulabilirken Türkiye' de durumun neden tam tersi olduğu sorusuyla başlamıştır. Gerçekten de Türkiye'de tarih mezunları, 2019 yılı istatistiklerine göre \%27 civarında olan genç işsiz oranından çok daha yüksek bir işsizlik oranına sahiptir. Bu sonucun ortaya çıkmasında, son yıllardan artan üniversite sayısına paralel olarak, tarih mezunu veren bölüm sayısının hızla artması, bölümlere alınan öğrenci sayılarının fazlalığı, ikili (gündüz, gece) öğretimi ve açık öğretim gibi yükseköğretim politikasından kaynaklanan nedenler bilinmektedir. Bu konu çok tartışılmıştır.

Hiç araştırılmamış ve tartışılmamış bir konu, söz konusu bu yüksek işsizlik oranlarında üniversite tarih eğitim programlarının tasarım ve uygulanmasında alınan kararların bir rolünün bulunup bulunmadığıdır. Bu araştırma bu boşluğu doldurmayı hedeflemiştir. Bu amaçla, tarih mezunu işsiz oranın çok düşük (\%5'ten az) olduğu ABD ile Türkiye'de üniversite tarih eğitim programlarının bütüncül (sistemik) bir bakış açısıyla karşılaştırılması hedeflenmiştir. Bu araştırma için sağlanan 90 günle sınırlı destek kapsamında bir sonuç alabilmek için, Türkiye ve $A B D$ 'den seçilen iki bölüm üzerinde örnek bir çalışma yapılmıştır. Bunlar, Hacettepe Üniversitesi Tarih Bölümü (Hacettepe Tarih) ile Western Illinois Üniversitesi Tarih Bölümüdür (Western Tarih).

Bu araştırmadan elde edilen belli başlı sonuçlar şöylece sıralanabilir:

1. Hem Hacettepe Tarih'te hem de Western Tarih'te lisans programı, disiplinler arası bir yaklaşımla tasarlanmıştır; programlar diğer sosyal bilimlerden giriş düzeyinde dersler içermektedir. Western Tarih'te farklı olarak öğrencilerin seçmesi muhtemel kariyer hedefleri göz önüne alınarak, program modüler hale getirilmiştir. Hacettepe tarihte modüler yapı söz konusu değildir. Ancak öğrenciler seçmeli dersler yoluyla kendi "modüllerini" oluşturabilmektedir. Burada öğrencilerin ne derece isabetli davrandıkları araştırılmaya muhtaçtır.

2. Farklı alanlarda iş bulabilme kriteri göz önüne alınarak yapılan program yeterlikleri karşılaştırması, Hacettepe Tarih'in daha iddialı olduğunu ortaya koymuştur. Program yeterlilik listesini gösteren tablodaki 2. ve 8. maddeler bu görüşü desteklemektedir.

3. Aynı kriter göz önüne alınarak yapılan, her iki programda ortak Tarih Metodolojisi (Historical Methods) dersinin öğrenme çıktıları karşılaştırması ise farklı sonuç vermiştir: Hacettepe Tarih öğrenme çıktılarını kendi başına çalışan "ideal tarihçi” göz önüne alarak belirlemişken, Western Tarih bunun yanında, gösterme (ispat etme), yazma, açıklama ve tartışma gibi etkili iletişim becerilerini öne çıkarmıştır.

4. Programların uygulama süreçleri bazında yapılan karşılaştırma, 3. maddedeki sonucun nedenini ortaya koymaktadır: Hacettepe Tarih, temel derslerden en önemlisi olan Tarih Metodolojisi dersini, 50-60 kişilik sınıflarda yapmak durumundayken, Western Tarih 710 kişilik sınıflarda yapmaktadır. Başka bir bakış açısından, Hacettepe Tarih'te öğretim üyesi 
başına düşen öğrenci sayısı 42 iken, Western Tarihte öğretim üyesi başına düşen öğrenci sayısı bunun beşte birinden daha azdır.

$\mathrm{Bu}$ sonuçlar karşısında yapılabilecekler kısa ve uzun vadeli olarak iki grupta toplanabilir. Uzun vadeli öneriler, Yükseköğretim politikasında kapsamlı bir değişiklik gerektirmektedir. Bu konu çeşitli platformlarda çok tartışılmış olup, sonuçsuzdur. O yüzden bu konuya burada girilmeyecektir.

Kısa vadeli öneriler, Türkiye'de Tarih bölümlerinin kendi üniversitelerinin desteğiyle yapabileceklerini içermektedir. Bunlar şöylece sıralanabilir:

1. İş dünyasının hızlı değişen dinamikleri karşısında, tarih eğitim programlarının daha sık gözden geçirilip güncellenmesi bunun için de "biz öğretimimizi yaparız mezunların iş bulup bulamaması bizi ilgilendirmez" anlayışından vaz geçilmesi.

2. Mezunların rahat iş bulabilmelerini sağlayacak bilgi ve becerileri kazanmalarına yönelik araştırma projeleri hazırlanıp, bunlara öğrencilerin aktif katılımının sağlanması. Üniversite BAP birimlerinin, TÜBITAK ve Türk Tarih Kurumu gibi araştırmalara fon sağlayan kuruluşların içinde eğitim unsuru olan (öğrenci katılımını öngören) projeleri öncelikle desteklemesi.

3. Üniversitelerin kadro tahsislerini, bu çalışmada olduğu gibi, uluslararası karşılaştırmalı bilimsel araştırmalar yaptırıp, buradan çıkacak sonuçlara göre yapmaları. Bilindiği üzere, YÖK, Norm Kadro Yönetmeliği ile kadro tahsislerinde üniversitelere yetki devri yapmıştır.

Sonuç olarak, bu çalışmada başlangıçta projede öngörülen hedefler tam olarak gerçekleştirilmiştir. Bununla birlikte, bu çalışmada elde edilen bulgular sadece iki bölümün karşılaştırılmasına dayalıdır. Daha geçerli sonuçlar için bu çalışma ile aynı metodu kullanan (sistem yaklaşımıyla yerinde gözlem öngören) daha geniş kapsamlı araştırmalara ihtiyaç vardır.

\section{Kaynakça}

Acun, R. (2010). Üniversitelerde Eğitim ve Araştırma İşlevlerinin Entegrasyonu. Hacettepe Üniversitesi Edebiyat Fakültesi Dergisi. 27/1, 2010, 1-14.

Acun, R. (2011). Sistem Yaklaşımıyla Tarihte Program Geliştirme. Kuram ve Uygulamada Eğitim Bilimleri. 11/2, 2011, 823-838.

Acun, R. (2018). From Social Network to Research Network: A Novel Approach for Integrating Teaching and Research Through Technology. Tojet: The Turkish Online Journal of Educational Technology, December 2018, Special Issue for IETC \& ITEC 191-198. Erişim (11.11.2019): http://www.tojet.net/special/2018_12_1.pdf. 
The AHA's Career Diversity for Historians (t.y.). Erişim (11.11.2019): https://www.historians.org/jobs-and-professional-development/career-diversity-forhistorians/about-career-diversity.

Bureau of Labor Statistics, U.S. Department of Labor, Occupational Outlook Handbook, Historians, 2018. Erişim (13.12. 2019): https://www.bls.gov/ooh/life-physical-andsocial-science/historians.htm.

Corbet, P. S., Janssen, V., Lund, J. M., Pfannstiel, T. \& Vickery, P. (2014). U.S. History, Houston: OpenStax. Erişim (26.11.2019): https://d3bxy9euw4e147.cloudfront.net/oscmsprodcms/media/documents/USHistory-OP IdjNctE.pdf.

Demircioğlu, ì. H. ve Demircioğlu, P. (Ed), (2017). Türkiye'de Tarih Eğitimi Araştırmaları El Kitabı, İstanbul: Pegem.

Educating Historians for Business: A Guide for Departments of History. Bloomington, Ind.: Organization of American Historians, 1983.

Hacettepe Tarih Lisans Programı (t.y.). Erişim (15.12.2018):

http://akts.hacettepe.edu.tr/ders listesi.php?prg ref=PRGRAM 0000000000000000 000000082 \&birim kod=353\&submenuheader=2\&prg kod=353.

Hacettepe Tarih Yüksek Lisans Programı (t.y.). Erişim (15.12.2018):

http://akts.hacettepe.edu.tr/ders listesi.php?prg ref=PRGRAM 0000000000000000 000000684\&birim kod=2134\&submenuheader=2\&prg kod=21341.

Kantrow, A. M. (1986). Why History Matters to Managers. Harvard Business Review, 64 (January-February, 1986), 81-88.

Mcnabb, J. (2017). B.A., History 2016-2017 Assessment of Student Learning Report. June 2017. Western Illinois Universty. Unpublished report.

Snowdon, G. (2010). What to do with a degree in history. The Guardian, Saturday 16 January 2010: Erişim (11.11.2019). https://www.theguardian.com/money/2010/jan/16/history-degree-careers

Sturtevant, Paul B. (2017). History Is Not a Useless Major: Fighting Myths with Data. Erişim (11.11.2019): https://www.historians.org/publications-and-directories/perspectiveson-history/april-2017/history-is-not-a-useless-major-fighting-myths-with-data.

Tarih öğretmenliği branş analizi (2016). Erişim (12.12.2018):

http://www.mebpersonel.com/haber/2016-subat-atamalari-tarih-ogretmenligibrans-analizi-h188374.html.

What Can You Do As A History Major? Erişim (11.12.2018): http://www.wiu.edu/cas/history/careeropp.php.

Woell, E. (2017). The 2016-2017 Assessment Report for the History Graduate Program, June 2017. Prepared by Director of Graduate Studies in History. Western Illinois Universty. Unpublished report. 